\title{
Laparoscopic Cholecystectomy in Acute Cholecystitis in Septuagenarians
}

\author{
João Paulo Araújo Teixeira ${ }^{1}$, Carlos Ribeiro ${ }^{1}$, Luís M. Moreira ${ }^{2}$, Fabiana de Sousa ${ }^{1}$, André Pinho ${ }^{1}$, \\ Luís Graça ${ }^{1}$, Costa Maia ${ }^{1}$
}

Corresponding author:

Prof. Joăo Paulo Araújo Teixeira Hospital S. Joăo,

Department of General Surgery Alameda Prof. Hernâni Monteiro 4200-319 Porto, Portugal E-mail: jpat@netcabo.pt
'Faculdade de Medicina da Universidade do Porto / Hospital de S. Joyo, Department of Surgery, Portugal ${ }^{2}$ Health School of Vila Nova de Gaia - Piaget Institute, Vila Nova de Gaia, Portugal \& RECI - Research Unit in Education and Community Intervention

\section{ABSTRACT}

Background: Although Laparoscopic Cholecystectomy (LC) has been used successfully in the treatment of biliary lithiasis in the elderly, its effectiveness in Acute Cholecystitis (AC) of high age groups is still questionable.

Material and Methods: A retrospective research was performed with 410 LC patients operated by AC from January 2006 to December 2013 in the department of surgery of Hospital S. Joăo. Two groups were considered: Group A - patients with 70 years old or older $(\mathrm{N}=91)$ and Group B - patients with less than 70 years old $(\mathrm{N}=319)$. The aim of the study is to compare morbidity and predictive factors for complications and conversion on these two groups.

Results: There was significant higher morbidity in group $A$ than in $B$ in the following items: surgical mortality ( $2.2 \%$ vs $0 \% ; p=0.011)$, overall postoperative complications $(25.3 \%$ vs $8.5 \% ; p<0.001)$, reoperations $(7.7 \%$ vs $1.6 \% ; p=0.007)$. The hospital stay $\leq 4$ days was lower in group $A$ than in $B(38.5 \%$ vs $49.8 \% ; p=0.045)$. The perioperative complications diagnosed during the LC (4.4\% vs $3.4 \% ; p=0.371)$, injuries of bile duct $(1.1 \%$ vs $0.9 \%$; $p=1.000$ ) and conversion (15.4 vs $9.4 \% ; p=0.125$ ), although higher in the elderly group (group A), was not statistically significant. Overall, independent predictors for post-operative complications were age, pulmonary disease and gangrenous cholecystitis. In group A the only significant factors were renal disease and gangrenous cholecystitis; and in group B the only significant factor was pulmonary disease.

Conclusion: Although LC in septuagenarian is accompanied by greater morbidity than in youngers, it should be considered as a safe and efficient procedure, and the first choice in surgery of AC in the elderly. However, in complex cases, percutaneous cholecystostomy should be recommended in a first stage, followed a few days later by LC.

Abbreviations: LC - Laparoscopic cholecystectomy; AC - Acute cholecystitis; A - group A; B - group B.

Key words: laparoscopic cholecystectomy in septuagenarians, acute cholecystitis

\section{INTRODUCTION}


lithiasis and can be particularly serious given thehigh incidence of co-morbidities in this age group (1).

Treatment of AC which does not give in to duly established medical therapy in the early hours after the diagnosis should be surgical, in order to avoid further complications. Riali (2) states that $25 \%$ of AC that were not operated on at an early stage forced rehospitalisation. This is identical to what's reported by Cameron (3), with $30 \%$ of rehospitalisation.

Laparoscopic Cholecystectomy (LC), after an initial phase in which it was considered a contraindication in AC (4), is currently the first choice in the treatment of this disease $(5,6,7,8)$.

Given the good results obtained with mini-invasive surgery in the elderly with uncomplicated biliary lithiasis $(9,10,11)$, it began to be recommended in acute cholecystitis of these patients but with no unanimity about its effectiveness. The current increase in life expectancy leads to include individuals aged 70 or older in those groups. In the U.S., it is estimated that by 2020 there will be an increase of incidence of life expectancy of $6.8 \%$ to 75 years and $2 \%$ to 80 years (12). However, most of the publications corresponding to LC in AC of the elderly considers as such patients from 65 years old $(13,14,15)$ or over $75(16)$ or 80 years old $(17)$. It seems to us that the age threshold of 70 years better reflects the real surgical risk in most patients with acute cholecystitis. Besides that, the comparative analysis of morbidity of $\mathrm{LC}$ in $\mathrm{AC}$ in those age groups with younger individuals operated on is not sufficiently clear.

This research compares the morbidity of septuagenarian patients with $\mathrm{AC}$ operated by $\mathrm{LC}$, with younger individuals.

\section{MATERIAL AND METHODS}

From 2006 to 2013, 410 LC for AC were performed in the General Surgery Department of HSJ. In this series, two groups were considered: Group A - patients with 70 years old or older ( $N=91,22.2 \%)$; and Group B - patients with less than 70 years old ( $N=319,77.8 \%)$. Group $A$ included 69 patients with 70 to 79 years old, 19 patients with 80 to 89 , and 3 patients with 90 to 99 . The average age in group A was $76.6( \pm 5.1)$ (ranging from 70 to 92 ) and in group B was 49.3 ( \pm 13.7 ) (ranging from 19 to 69 ).

The group characteristics are presented on table 1.

There were 53 men (58.2\%) and 38 women (41.8\%) in group $A$ and 151 men (47.3\%) and 168 women $(52.7 \%)$ in group B. Jaundice appeared in 16 cases (3.9\%) [7 in group A $(7.7 \%)$ and 9 in group $B(2.8 \%)$ ] due to lithiasis in the bile duct; the stones were removed by endoscopic sphincterotomy 3 to 4 days prior to the LC.

In group A there were 42 cases $(46.2 \%)$ of ASA III and IV and $43(13.5 \%)$ in group $B(p<0.001)$.

Considering the comorbidities, diabetes and cardiovascular diseases were significantly more frequent in group $A$ than in group $B(p<0.001)$. Pulmonary disease was identical in both groups and renal disease, although most frequent in group $A$, it was not statistically significant $(p=0.071)$.

The comparative study was conducted in the 2 groups with regard to mortality, per and postoperative complications, bile duct injury, timing of surgery, incidence of conversion, hospital stay and predictive factors associated to complications.

Surgery was performed in those patients for whom there was no clinical improvement in the early hours after the diagnosis following duly established medical therapy. In 8 cases in group A, percutaneous cholecystostomy guided by echography was performed in the first stage, followed six days later by laparoscopic cholecystectomy.

The diagnosis of AC was made according to clinical, imaging and analytical data and was confirmed by

Table 1 - Characteristics of patients

\begin{tabular}{|c|c|c|c|c|c|}
\hline & & $\begin{array}{c}\text { Overall } \\
(\mathrm{N}=410)\end{array}$ & $\begin{array}{c}\text { Group } A \geq 70 \\
(N=91)\end{array}$ & $\begin{array}{c}\text { Group } B<70 \\
(\mathrm{~N}=319)\end{array}$ & p-value \\
\hline Mean age & & $55.3( \pm 16.8)$ & $76.6( \pm 5.1)$ & $49.3( \pm 13.7)$ & $<0.001$ \\
\hline Gender & $\begin{array}{l}\text { Men } \\
\text { Women }\end{array}$ & $\begin{array}{l}204(49.8 \%) \\
206(50.2 \%)\end{array}$ & $\begin{array}{l}53(58.2 \%) \\
38(41.8 \%)\end{array}$ & $\begin{array}{l}151(47.3 \%) \\
168(52.7 \%)\end{array}$ & 0.075 \\
\hline ASA III y IV & & $85(20.7 \%)$ & $42(46.2 \%)$ & $43(13.5 \%)$ & $<0.001$ \\
\hline Jaundice & & $16(3.9 \%)$ & $7(7.7 \%)$ & $9(2.8 \%)$ & 0.059 \\
\hline Comorbidities & $\begin{array}{l}\text { Diabetes } \\
\text { Cardiovascular } \\
\text { Pulmonary } \\
\text { Renal }\end{array}$ & $\begin{array}{c}57(13.9 \%) \\
117(28.5 \%) \\
21(5.1 \%) \\
17(4.1 \%)\end{array}$ & $\begin{array}{c}27(29.7 \%) \\
46(50.5 \%) \\
5(5.5 \%) \\
7(7.7 \%)\end{array}$ & $\begin{array}{c}30(9.4 \%) \\
71(22.3 \%) \\
16(5.0 \%) \\
10(3.1 \%)\end{array}$ & $\begin{array}{c}<0.001 \\
<0.001 \\
0.792 \\
0.071\end{array}$ \\
\hline
\end{tabular}


pathology. The surgical technique of LC was reported in a previous report (18). Patients with biliary peritonitis were excluded from this study and operated by open cholecystectomy.

Data analysis was based on descriptive statistics and the differences between the two groups were evaluated based on the binomial test for two proportions. We used multivariate logistic regression analysis to evaluate the impact of several independent predictive factors - gender, gangrenous cholecystitis, timing of surgery, comorbidities - on postoperative complications and conversion. Significant values for $p \leq 0.05$ were considered.

\section{RESULTS}

The comparison of the results in the elderly and younger patients is presented on table 2.

There were 15 (3.7\%) overall perioperative complications diagnosed during the LC $-4(4.4 \%)$ in group $A$ and $11(3.4 \%)$ in group $B(p=0.371)$ - and $50(12.2 \%)$ overall postoperative complications - 23 (25.3\%) in group $A$ and $27(8.5 \%)$ in group B $(p<0.001)$. Thirty-two of these $(7.8 \%)$ were postoperative surgical complications - 11 (12.1\%) in group A and 21 (6.6\%) in group B ( $p=0.128)$ - and $18(4.4 \%)$ were postoperative medical complications 12 (13.2\%) in group A and 6 (1.9\%) in group $B(p<0.001)$.

In perioperative complications diagnosed during the LC, it is worth mentioning the biliary lesions, in particular 2 common duct injuries in Group B and 3 lacerations of the cystic duct ( 2 in group $A$ and 1 in $B$ ); the latter occurred during the introduction of the cannula for cholangiography (B) and in the other two

Table 2 - Comparison of the results in the elderly and younger patients

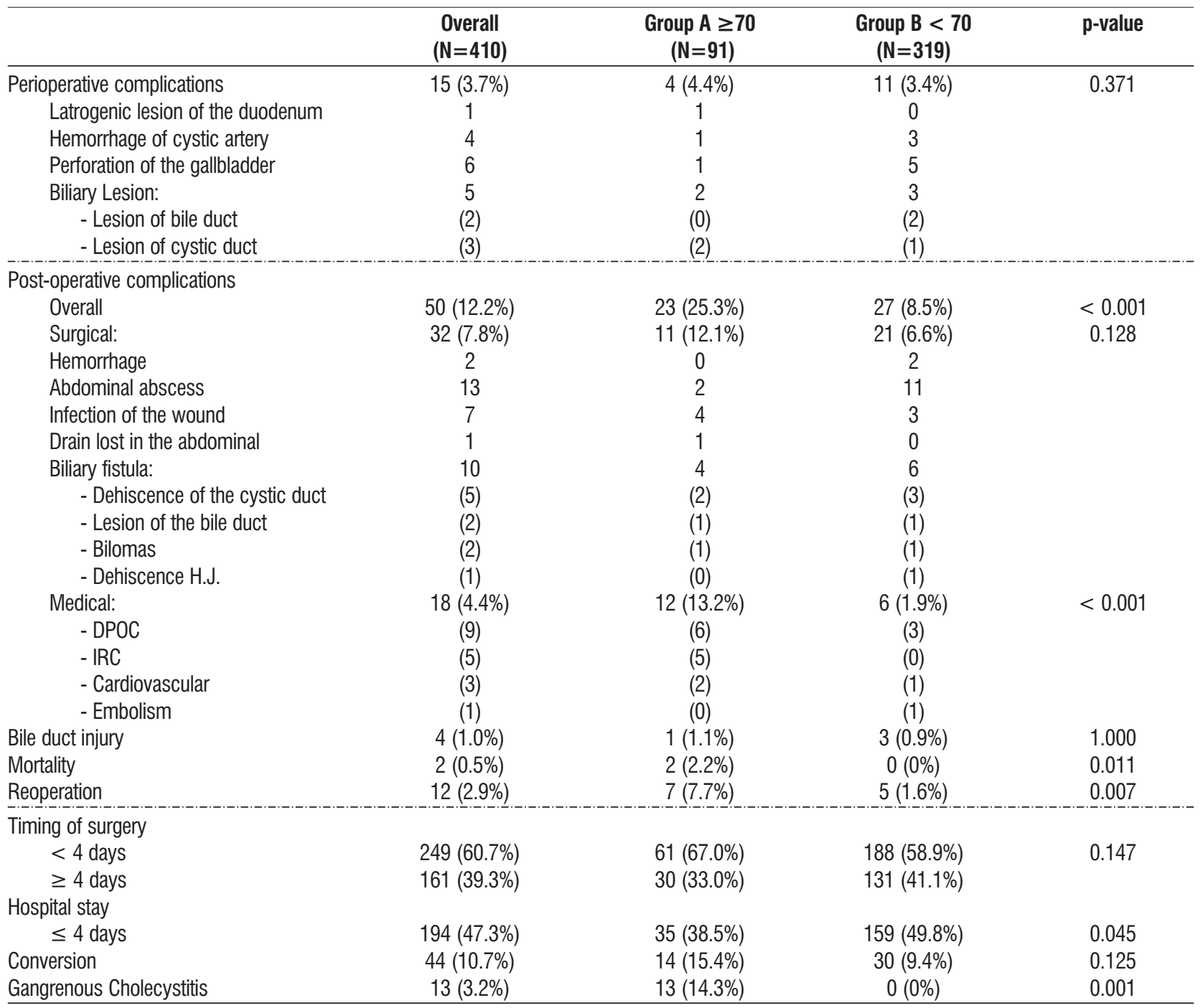


(A) in scleroatrophic gallbladders with Mirizzi syndrome. There were also 6 gallbladders perforations ( 1 in group $A$ and 5 in B) with abdominal spillage of the stones. In the post-operative period there were 2 common duct injuries ( 1 in Group A and 1 in the B); 1 Hepaticojejunostomy dehiscence (B) performed during the conversion; there also occurred 5 dehiscences corresponding to ligature of the cystic duct ( 2 in group $A$ and 3 in B) and 13 abdominal abscesses ( 2 in group $A$ and 11 in $B$ ). There was a higher number of respiratory and renal complications in group $A$.

There was a total of $12(2.9 \%)$ reoperations: $7(7.7 \%)$ in group $A$ and $5(1.6 \%)$ in group $B(p=0.007)$. They consisted of 5 laparotomies due to: 2 dehiscence of cystic duct (A), 1 dehiscence of HJ (B), 1 biloma (A), 1 abdominal abscess (A); 2 Hepaticojejunostomy ( 1 in $A$ and 1 in $B$ due to lesion of the bile duct); 1 Splenectomy, due to iatrogenic lesion of the spleen (B). Besides these, 1 drainage of abdominal abscess (A) was performed by laparoscopy and 1 removal of a drain lost in the abdomen during laparoscopic cholecystectomy.

The timing of surgery (after diagnosis at the emergency department) was less than 4 days to 249 $(60.7 \%)$ patients - 61 (67\%) in group A and $188(58.9 \%)$ in $\mathrm{B}$; and more or equal to 4 days to $161(39.3 \%)$ patients - $30(33.0 \%)$ in group A and $131(41.1 \%)$ in B $(p=0.147)$.

The overall mortality was $2(2.2 \%)$, both in group A $(p=0.011)$. The causes of death were respiratory failure and stroke, septic shock and pneumonia, injury of bile duct, in patients operated with 80 and 86 years old; all of them with gangrenous cholecystitis and included in the ASA IV.

The overall conversion was 44 (10.7\%): 14 (15.4\%) in group $A$ and $30(9.4 \%)$ in $B(p=0.125)$. Multiple causes led to conversion: unclear anatomy of the pedicle, perforation of the gallbladder with abdominal spillage of the stones, haemorrhage, biliary lesions, iatrogenic injury to the duodenum, scoliosis and hemodynamic changes during the pneumoperitoneum.

The hospital stay was less than or equal to 4 days to 194 (47.3\%) patients: 35 (38.5\%) in group A and 159 $(49.8 \%)$ in $B(p=0.045)$.

According to the multivariate logistic regression analysis (table 3 ), the independent predictive factors of post-operative complications that were statistically significant in all the 410 patients were: age $(O R=[0.5$ $(0.2-0.9)] p=0.035)$, pulmonary disease $(\mathrm{OR}=[0.3(0.1$ $0.8)] ; p=0.014)$ and gangrenous cholecystitis $(O R=[0.2$ (0.1-0.7)]; $p=0.011$ ). With regard to conversion, the two statistically significant independent predictive factors were pulmonary disease $(\mathrm{OR}=[0.2(0.1-0.5)]$; $\mathrm{p}=0.002)$ and gangrenous cholecystitis $(O R=[0.0(0.0-$ $0.3)$ ]; $p<0.001$ ).

In tables 4 and 5 we present the multivariate logistic regression analysis for each of the groups $A$ and $B$, respectively.

In Group A, the independent predictive factors of post-operative complications that were statistically significant were renal disease $(O R=[0.2(0.03-0.9)] ; p=$ 0.038 ) and gangrenous cholecystitis (OR $=[0.2$ (0.1$0.8)$ ]; $p=0.018$ ). With regard to conversion, only the gangrenous cholecystitis was found to be a statistically significant independent predictive factor $(\mathrm{OR}=[0.0$ (0.0-0.3)]; $p<0.001)$.

In Group B, pulmonary disease was the only one statistically significant independent predictive factor of post-operative complications $(\mathrm{OR}=[0.2(0.1-0.8)] ; \mathrm{p}=$

Table 3 - Factors influencing the risk of post-operative complications and Conversion

\begin{tabular}{|c|c|c|c|c|c|c|c|c|c|}
\hline & \multirow[b]{2}{*}{$\begin{array}{c}\text { Overall } \\
(\mathrm{N}=410)\end{array}$} & \multicolumn{4}{|c|}{ Factors influencing the risk of post-operative complications } & \multicolumn{4}{|c|}{ Factors influencing Conversion } \\
\hline & & $\begin{array}{c}\text { With } \\
\text { complications } \\
(\mathrm{N}=50)\end{array}$ & $\begin{array}{c}\text { No } \\
\text { complications } \\
(\mathrm{N}=360)\end{array}$ & $\begin{array}{c}\text { Odds ratio } \\
\text { (95\% confidence } \\
\text { interval) }\end{array}$ & p-value & $\begin{array}{c}\text { With } \\
\text { conversions } \\
(\mathrm{N}=44)\end{array}$ & $\begin{array}{c}\text { No } \\
\text { conversions } \\
(\mathrm{N}=366)\end{array}$ & $\begin{array}{c}\text { Odds ratio } \\
\text { (95\% confidence } \\
\text { interval) }\end{array}$ & p-value \\
\hline \multicolumn{10}{|l|}{ Demographics } \\
\hline Age $\geq 70$ & $91(22.2 \%)$ & $23(46 \%)$ & $68(18,9 \%)$ & $0.5(0.2-0.9)$ & 0.035 & $14(31.8 \%)$ & $77(21.0 \%)$ & $2.9(0.8-10.4)$ & 0.104 \\
\hline Gender (male) & $204(49.8 \%)$ & $24(48 \%)$ & $178(49.4 \%)$ & $1.1(0.6-2.0)$ & 0.876 & $18(40.9 \%)$ & $180(49.2 \%)$ & $0.7(0.4-1.5)$ & 0.427 \\
\hline \multicolumn{10}{|l|}{ Comorbidity } \\
\hline Diabetes & $57(13.9 \%)$ & $11(22.0 \%)$ & $46(12.8 \%)$ & $0.8(0.3-1.8)$ & 0.579 & $6(13.6 \%)$ & $51(13.9 \%)$ & $2.0(0.5-7.8)$ & 0.328 \\
\hline Cardiovascular & $117(28.5 \%)$ & $22(44.0 \%)$ & 95 (26.4\%) & $0.6(0.3-1.2)$ & 0.163 & $18(40.9 \%)$ & $99(27.0 \%)$ & $0.5(0.2-1.2)$ & 0.118 \\
\hline Pulmonary & $21(5.1 \%)$ & $6(12.0 \%)$ & $15(4.2 \%)$ & $0.3(0.1-0.8)$ & 0.014 & $6(13.6 \%)$ & $15(4.1 \%)$ & $0.2(0.1-0.5)$ & 0.002 \\
\hline Renal & $17(4.1 \%)$ & $5(10.0 \%)$ & $12(3.3 \%)$ & $0.4(0.1-1.4)$ & 0.146 & $2(4.5 \%)$ & $15(4.1 \%)$ & $1.6(0.2-10.2)$ & 0.623 \\
\hline \multicolumn{10}{|l|}{ Timing of Surgery: } \\
\hline$\geq 4$ days & $161(39.3 \%)$ & $16(32.0 \%)$ & $145(40.3 \%)$ & $1.5(0.8-2.9)$ & 0.245 & $22(50.0 \%)$ & $139(38.0 \%)$ & $0.5(0.3-1.1)$ & 0.107 \\
\hline \multicolumn{10}{|l|}{ Pathology } \\
\hline Gang. Chol. & $13(3.2 \%)$ & 7 (14.0\%) & $6(1.7 \%)$ & $0.2(0.1-0.7)$ & 0.011 & $11(25.0 \%)$ & $2(0.5 \%)$ & $0.0(0.0-0.03)$ & $<0.001$ \\
\hline
\end{tabular}


0.022). With regard to conversion, the two significant factors were cardiovascular disease $(\mathrm{OR}=[0.4(0.2-0.8)]$; $\mathrm{p}=0.018)$ and pulmonary disease $(\mathrm{OR}=[0.1(0.03-0.4)]$; $p<0.001)$.

\section{DISCUSSION}

It is important to evaluate our results comparing $\mathrm{LC}$ in septuagenarians to younger patients. We found worse results with statistical significance in the group $\geq 70$ years old with regard to: post-operative complications in general, medical complication, mortality, reoperations, hospital stay and gangrenous cholecystitis. We found no significant differences on perioperative complications, surgical complications, bile duct injury, timing of surgery and conversion.

It is important to point out the higher incidence of coexisting diseases in Group A than in B, particularly with regard to cardiovascular diseases and diabetes, which had obvious repercussions in the greater morbidity reported in this group of patients.

The overall post-operative complications in both groups were lower than recorded in previous reports $(16,17)$.

Among such complications it is worth mentioning the common bile duct lesions $(1.1 \%$ in group $A$ and $0.3 \%$ in group $B)$. These values are similar to those cited by Navez (1.1\%) (19), though these latter correspond to acute cholecystitis series operated on regardless of age. They are essentially caused by mistake of interpretation of the bile duct with the cystic duct in the course of the dissection inherent to intense inflammation processes of the biliary pedicle. To carry out its prevention, routine per-operative cholangiographywas proposed (20); although without unanimity (21). This examination was done selectively by our group only in the cases of unclear anatomy; it is important to mention that such injuries can occur after performing cholangiography, as

Table 4 - GROUP A: Factors influencing the risk of post-operative complications and conversion

\begin{tabular}{|c|c|c|c|c|c|c|c|c|c|}
\hline & \multirow[b]{2}{*}{$\begin{array}{l}\text { Group A } \\
(\mathrm{N}=91)\end{array}$} & \multicolumn{4}{|c|}{ Factors influencing the risk of post-operative complications } & \multicolumn{4}{|c|}{ Factors influencing Conversion } \\
\hline & & $\begin{array}{c}\text { With } \\
\text { complications } \\
(\mathrm{N}=23)\end{array}$ & $\begin{array}{c}\text { No } \\
\text { complications } \\
(\mathrm{N}=68)\end{array}$ & $\begin{array}{c}\text { Odds ratio } \\
\text { (95\% confidence } \\
\text { interval) }\end{array}$ & p-value & $\begin{array}{c}\text { With } \\
\text { conversions } \\
(\mathrm{N}=14)\end{array}$ & $\begin{array}{c}\text { No } \\
\text { conversions } \\
(\mathrm{N}=77)\end{array}$ & $\begin{array}{c}\text { Odds ratio } \\
\text { (95\% confidence } \\
\text { interval) }\end{array}$ & p-value \\
\hline \multicolumn{10}{|l|}{ Demographics } \\
\hline Gender (male) & $53(58.2 \%)$ & $11(47.8 \%)$ & $42(61.8 \%)$ & $0.6(0.2-1.9)$ & 0.404 & $7(50.0 \%)$ & 46 (59.7\%) & $1.1(0.2-7.9)$ & 0.931 \\
\hline \multicolumn{10}{|l|}{ Comorbidity } \\
\hline Diabetes & $27(29.7 \%)$ & $8(34.8 \%)$ & $19(27.9 \%)$ & $0.7(0.2-2.0)$ & 0.465 & $5(35.7 \%)$ & $22(28.6 \%)$ & $1.1(0.1-9.3)$ & 0.906 \\
\hline Cardiovascular & $46(50.5 \%)$ & $14(60.9 \%)$ & $32(47.1 \%)$ & $0.5(0.2-1.5)$ & 0.203 & $7(50.0 \%)$ & $39(50.6 \%)$ & $1.9(0.3-14.6)$ & 0.508 \\
\hline Pulmonary & $5(5.5 \%)$ & $2(8.7 \%)$ & $3(4.4 \%)$ & $0.3(0.04-2.3)$ & 0.241 & $0(0 \%)$ & $5(6.5 \%)$ & -- & 0.999 \\
\hline Renal & $7(7.7 \%)$ & $4(17.4 \%)$ & $3(4.4 \%)$ & $0.2(0.03-0.9)$ & 0.038 & $2(14.3 \%)$ & $5(6.5 \%)$ & $0.2(0.01-2.3)$ & 0.177 \\
\hline \multicolumn{10}{|l|}{ Timing of surgery: } \\
\hline$\geq 4$ days & $30(33.0 \%)$ & $6(26.1 \%)$ & $24(35.3 \%)$ & $2.2(0.7-7.2)$ & 0.207 & $6(42.9 \%)$ & $24(31.2 \%)$ & $0.2(0.02-1.8)$ & 0.137 \\
\hline \multicolumn{10}{|l|}{ Pathology } \\
\hline Gang. Chol. & $13(14.3 \%)$ & $7(30.4 \%)$ & $6(8.8 \%)$ & $0.2(0.1-0.8)$ & 0.018 & $11(78.6 \%)$ & $2(2.6 \%)$ & $0.0(0.0-0.04)$ & $<0.001$ \\
\hline
\end{tabular}

Table 5 - GROUP B: Factors influencing the risk of post-operative complications and conversion

\begin{tabular}{|c|c|c|c|c|c|c|c|c|c|}
\hline & \multirow[b]{2}{*}{$\begin{array}{l}\text { Group B } \\
(\mathrm{N}=319)\end{array}$} & \multicolumn{4}{|c|}{ Factors influencing the risk of post-operative complications } & \multicolumn{4}{|c|}{ Factors influencing conversion } \\
\hline & & $\begin{array}{c}\text { With } \\
\text { complications } \\
(\mathrm{N}=27)\end{array}$ & $\begin{array}{c}\text { No } \\
\text { complications } \\
(\mathrm{N}=292)\end{array}$ & $\begin{array}{c}\text { Odds ratio } \\
\text { (95\% confidence } \\
\text { interval) }\end{array}$ & p-value & $\begin{array}{c}\text { With } \\
\text { conversions } \\
(\mathrm{N}=30)\end{array}$ & $\begin{array}{c}\text { No } \\
\text { conversions } \\
(\mathrm{N}=289)\end{array}$ & $\begin{array}{c}\text { Odds ratio } \\
\text { (95\% confidence } \\
\text { interval) }\end{array}$ & $\mathrm{p}$-value \\
\hline \multicolumn{10}{|l|}{ Demographics } \\
\hline Gender (male) & $151(47.3 \%)$ & $15(55.6 \%)$ & $136(46.6 \%)$ & $1.5(0.7-3.3)$ & 0.356 & $11(36.7 \%)$ & $140(48.4 \%)$ & $0.7(0.3-1.6)$ & 0.367 \\
\hline \multicolumn{10}{|l|}{ Comorbidity } \\
\hline Diabetes & $30(9.4 \%)$ & $3(11.1 \%)$ & $27(9.2 \%)$ & $0.9(0.2-3.4)$ & 0.893 & $1(3.3 \%)$ & $29(10.0 \%)$ & $3.6(0.5-28.6)$ & 0.226 \\
\hline Cardiovascular & $71(22.3 \%)$ & $8(29.6 \%)$ & $63(21.6 \%)$ & $0.6(0.3-1.6)$ & 0.321 & $11(36.7 \%)$ & $60(20.8 \%)$ & $0.4(0.2-0.8)$ & 0.018 \\
\hline Pulmonary & $16(5.0 \%)$ & $4(14.8 \%)$ & $12(4.1 \%)$ & $0.2(0.1-0.8)$ & 0.022 & $6(20.0 \%)$ & $10(3.5 \%)$ & $0.1(0.03-0.4)$ & $<0.001$ \\
\hline Renal & $10(3.1 \%)$ & $1(3.7 \%)$ & $9(3.1 \%)$ & $1.5(0.1-15.2)$ & 0.732 & $0(0 \%)$ & $10(3.5 \%)$ & $-x_{-1}^{-}$ & 0.999 \\
\hline \multicolumn{10}{|l|}{ Timing of surgery: } \\
\hline$\geq 4$ days & $131(41.1 \%)$ & $10(37.0 \%)$ & $121(41.4 \%)$ & $1.3(0.6-2.9)$ & 0.569 & $16(53.3 \%)$ & $115(39.8 \%)$ & $0.7(0.3-1.5)$ & 0.297 \\
\hline \multicolumn{10}{|l|}{ Pathology } \\
\hline Gang. Chol. & $0(0 \%)$ & --- & --- & --- & --- & --- & --- & --- & --- \\
\hline
\end{tabular}


happened in two of our cases.

There were also biliary leaks causing bilomas ( 1 in group $A$ and 1 in B) without bile duct injury and inherent to accessory bile ducts or liver surface of the gallbladder or, yet more seriously, corresponding to the leakage of the cystic stump ( 2 in group A and 3 in $B)$; so the greatest care must be taken using more than one clip for the ligature of that duct.

Conversion, also without statistical significance, was higher in group A (15.4\%) than in B (9.4\%), according to previous reports (17). It must be mentioned that those values are lower than those reported in AC operated by laparoscopy in the elderly (17); the incidence of conversion registered in $\mathrm{LC}$ for $\mathrm{AC}$ analyzed regardless of age is $11 \%(19)$ and $12 \%(22)$.

We performed the $L C$ as early as possible in relation to the timing of diagnosis, since this seems to lead to lower incidence of conversion $(23,24)$, although there is no total unanimity on this subject $(25,26)$. In the late cholecystectomy, inflammation with hypervascularization, abscess formation and necrosis, make the dissection difficult and can cause haemorrhage and biliary lesions. The time of surgery did not prove predictive factors in complications and the conversion of the two groups.

In the face of complex situations one should not hesitate to convert to laparotomy and thisshould not be considered a sign of inexperience but of common sense.

The abdominal abscesses and infections in the wound were probably inherent to the spillage of the stones and infected bile occasioned by perforation of the gallbladder, especially in gangrenous cholecystitis, although we always carried out the gallbladder removal by wrapping it in a plastic bag.

Reoperations that were more frequent in Group A than in $B(7.7 \%$ vs $1.6 \%)$ were caused essentially by bile injuries, abscesses and haemoperitoneum. It should be noted that in one abscess (group A) we proceeded to its drainage by laparoscopy; in 11 abdominal abscesses manifested postoperatively (group B), percutaneous drainage was done guided by echography. The performance of $2 \mathrm{HJ}$ ( 1 ingroup $A$ and 1 in B) that occurred postoperatively due to common duct injury should be pointed out.It is also important to highlight an Hepaticojejunostomy postoperative dehiscence carried out during the conversion in which nothing else was possible to do than abdominal drainage followed by death.

The hospital stay was longer in the elderly group (in group A, 38.5\% had a hospital stay $\leq 4$ days and in group $B$ this percentage was $49.8 \%$ ), as previously reported
(17), certainly due to the higher number of coexisting diseases in that age group, particularly diabetes and cardiovascular disease.

We found higher mortality in the older group $(2.2 \%$ vs $0 \%$ ), although with values lower than those reported in other publications [ $4.8 \%$ vs $0.5 \%(16)$ and $4 \%$ vs $1 \%(17)]$; postoperative deaths were attributed to coexisting cardiorespiratory diseases and sceptical complications; all of them were included in ASAIV group with gangrenous cholecystitis.

It should be mentioned that, in the future, it would be prudent to perform percutaneous cholecystostomy drainage guided by echography more specially in critically ASAIV patients in a first stage, followed a few days later by LC, which we did in 8 cases, according to Macri (27).

It is important to mention the multivariate logistic regression analysis carried out not only in relation to the totality of the 410 individuals operated on, but also for both groups separately, A and B.

Age, pulmonary disease and gangrenous cholecystitis were independent predictive factors for postoperative complications in all the 410 operated on, though the same did not happen togender [valued by Sippey (28)] and the timing of surgery. In group A the only significant factors were renal disease and gangrenous cholecystitis; and in group B the only significant factorwas pulmonary disease.

Gangrenous cholecystitis was particularly evident as a predictive independent factor for conversion, according to what has been mentioned in previous publications (17), and pulmonary disease in the younger group.

Thus, our results show that, although LC in AC septuagenarians shows greater morbidity than in younger individuals, nevertheless it presents itself as an efficient and safe technique in surgery of that disease, allowing this higher age group to benefit from the advantages of mini-invasive surgery.

We should mention that our investigation has the limitations inherent to any retrospective study. On the other hand, although LC has been included in the experience of a single department, its implementation was carried out by various surgeons.

\section{CONCLUSION}

$\mathrm{LC}$ in the elderly is feasible and effective, though it has greater morbidity than in younger individuals. However, the results fully justify our choice in the treatment of acute cholecystitis in this age group. Nevertheless, it seems right to recommend percuta- 
neous cholecystostomy in complex cases in a first stage, followed a few days later by LC.

\section{Conflicts interests}

The authors declare that they have no conflict of interests.

\section{Authors' contributions}

JPAT and CR devised the study and drafted the manuscript. LM performed the statistical analysis.

\section{Authors' information}

JPAT: PhD associated professor with aggregation at FMUP; chief of Surgery of Hospital S. João; FACS.

CR: MD assistant of surgery Hospital S. João

FS: MD assistant of surgery Hospital S. João

AP: MD assistant of surgery Hospital S. João

LG: Chief of surgery Hospital S. João

CM: Chief of department of surgery Hospital S. João

LM: PhD professor at the Health School of Vila Nova de Gaia - Piaget Institute, Portugal \& RECl - Research Unit in Education and Community Intervention.

\section{REFERENCES}

1. Cho JY, Han H-S, Yoon Y-S, Ahn KS. Risk factors for acute cholecystitis and a complicated clinical course in patients with symptomatic cholelithiasis. Arch Surg. 2010 Apr;145(4):329-33; discussion 333. doi: 10.1001/archsurg.2010.35.

2. Riall TS, Zhang D, Townsend CM Jr, Kuo YF, Goodwin JS. Failure to perform cholecystectomy for acute cholecystitis in elderly patients is associated with increased morbidity, mortality, and cost. J Am Coll Surg. 2010 May;210(5):668-77, 677-9. doi: 10.1016/j.jamcollsurg. 2009.12.031.

3. Cameron IC, Chadwick C, Phillips J, Johnson AG. Acute cholecystitis-room for improvement? Ann R Coll Surg Engl. 2002 Jan;84(1):10-3.

4. Cuschieri A, Berci G. Laparoscopic biliary surgery. Ed. Blackwell Scientific Publications. 1991. pg. 381.

5. Araújo Teixeira JP, Saraiva AC, Costa Cabral A, Barros H, Rocha Reis J, Araújo Teixeira A. Laparoscopy or laparotomy in acute cholecystitis (200 cases). Comparison of the results and factors predictive of conversion Chirurgie. 1999 Nov;124(5):529-35. French

6. Teixeira JP, Ribeiro C, Pinto A, Goulart A, Maia JC, Pimenta A. Surgical management of acute cholecystitis (experience of 249 cases). Hepatogastroenterology. 2011 Mar-Apr;58(106):281-4.

7. Teixeira J, Ribeiro C, Moreira LM, de Sousa F, Pinho A, Graça L, et al. Laparoscopic cholecystectomy and open cholecystectomy in acute cholecystitis: critical analysis of 520 cases. Acta Med Port. 2014 Nov-Dec;27(6):685-91. Epub 2014 Dec 30. Portuguese

8. Coccolini F, Catena F, Pisano M, Gheza F, Fagiuoli S, Di Saverio S, et al. Open versus laparoscopic cholecystectomy in acute cholecystitis. Systematic review and meta-analysis. Int J Surg. 2015 Jun;18:196204. doi: 10.1016/j.jisu.2015.04.083. Epub 2015 May 6.

9. Dennis R, Guy R, Bajwa F. Laparoscopic cholecystectomy in patients over 80 years is feasible and safe: analysis of 68 consecutive cases. World Journal of Laparoscopic Surgery; 2009;2(2):22.
10. Pavlidis TE, Marakis GN, Symeonidis N, Psarras K, Ballas K, Rafailidis S, Sakantamis AK. Considerations concerning laparoscopic cholecystectomy in the extremely elderly. J Laparoendosc Adv Surg Tech A. 2008 Feb;18(1):56-60. doi: 10.1089/lap.2007.0037.

11. Nielsen LB1, Harboe KM, Bardram L. Cholecystectomy for the elderly: no hesitation for otherwise healthy patients. Surg Endosc. 2014 Jan;28(1):171-7. doi: 10.1007/s00464-013-3144-8. Epub 2013 Aug 31.

12. U.S. Bureau of Census Current population reports, series P-25, N.952, projections of the population of the United States by age, sex, and race: 1983-2080. U.S. Government Printing Office, Washington, DC.

13. do Amaral PC, Azaro Filho Ede M, Galvăo TD, Ettinger JE, Silva Reis JM, Lima M, et al. Laparoscopic cholecystectomy for acute cholecystitis in elderly patients. JSLS. 2006 Oct-Dec;10(4):479-83.

14. Bueno Lledó J, Vaqué Urbaneja J, Herrero Bernabeu C, Castillo García E, Carbonell Tatay F, Baquero Valdelomar R, et al. Acute cholecystitis and laparoscopic cholecystectomy in the elderly Cir Esp. 2007 Apr; 81(4):213-7. Spanish

15. Teixeira JP, Ribeiro C, Pinho A, Graça L, Moreira LM, Maia JC. Laparoscopic cholecystectomy in acute cholecystitis in the elderly. Hepatogastroenterology. 2014 Jan-Feb;61(129):18-21.

16. Kirshtein B, Bayme M, Bolotin A, Mizrahi S, Lantsberg L. Laparoscopic cholecystectomy for acute cholecystitis in the elderly: is it safe? Surg Laparosc Endosc Percutan Tech. 2008 Aug;18(4):334-9. doi: 10.1097/ SLE.0b013e318171525d.

17. Nikfarjam M, Yeo D, Perini M, Fink MA, Muralidharan V, Starkey G, Jones RM, Christophi C. Outcomes of cholecystectomy for treatment of acute cholecystitis in octogenarians. ANZ J Surg. 2014 Dec;84(12):943-8. doi: 10.1111/ans.12313. Epub 2013 Aug 1.

18. Araújo Teixeira JP. How to perform a safe laparoscopic cholecystectomy in Minimally invasive abdominal surgery. Lisboa: Instituto Piaget; 2010. p. 67-82.

19. Navez B, Ungureanu F, Michiels M, Claeys D, Muysoms F, Hubert C, et al. Surgical management of acute cholecystitis: results of a 2-year prospective multicenter survey in Belgium. Surg Endosc. 2012 Sep;26(9):2436-45. Epub 2012 Mar 10.

20. Berci G, Hunter J, Morgenstern L, Arregui M, Brunt M, Carroll B, et al. Laparoscopic cholecystectomy: first, do no harm; second, take care of bile duct stones. Surg Endosc. 2013 Apr;27(4):1051-4. doi: 10.1007/ s00464-012-2767-5. Epub 2013 Jan 26.

21. Hamad MA, Nada AA, Abdel-Atty MY, Kawashti AS. Major biliary complications in 2,714 cases of laparoscopic cholecystectomy without intraoperative cholangiography: a multicenter retrospective study. SurgEndosc. 2011 Dec;25(12):3747-51.

22. Moyson J, Thill V, Simoens Ch, Smets D, Debergh N, Mendes da Costa P. Laparoscopic cholecystectomy for acute cholecystitis in the elderly: a retrospective study of 100 patients. Hepatogastroenterology. 2008 Nov-Dec;55(88):1975-80.

23. Teixeira JP, Saraiva AC, Cabral AC, Barros H, Reis JR, Teixeira A. Conversion factors in laparoscopic cholecystectomy for acute cholecystitis. Hepatogastroenterology. 2000 May-Jun;47(33):626-30.

24. González-Rodríguez FJ, Paredes-Cotoré JP, Pontón C, Rojo Y, Flores E, Luis-Calo ES, et al. Early or delayed laparoscopic cholecystectomy in acute cholecystitis? Conclusions of a controlled trial. Hepatogastroenterology. 2009 Jan-Feb;56(89):11-6.

25. Gurusamy KS, Samraj K. Early versus delayed laparoscopic cholecystectomy for acute cholecystitis. Cochrane Database Syst Rev. 2006 Oct 18;(4):CD005440.

26. Knight JS, Mercer SJ, Somers SS, Walters AM, Sadek SA, Toh SK. Timing of urgent laparoscopic cholecystectomy does not influence conversion rate. Br J Surg. 2004 May;91(5):601-4.

27. Macrì A, Scuderi G, Saladino E, Trimarchi G, Terranova M, Versaci A, et al. Acute gallstone cholecystitis in the elderly: treatment with emergency ultrasonographic percutaneous cholecystostomy and interval laparoscopic cholecystectomy. SurgEndosc. 2006 Jan; 20(1):88-91.

28. Sippey M, Grzybowski M, Manwaring ML, Kasten KR, Chapman WH, Pofahl WE, et al. Acute cholecystitis: risk factors for conversion to an open procedure. J Surg Res. 2015 Dec;199(2):357-61. 